Annual Report

1987-1988

by

D. D. Edie, G. C. Lickfield, M. J. Drews, M. S. Ellison

L. E. Allen, J. R. McCollum and H. L. Thomas

ADVANCED ENGINEERING FIBERS LABORATORY

CLEMSON UNIVERSITY

CLEMSON, S.C. $29634-0909$

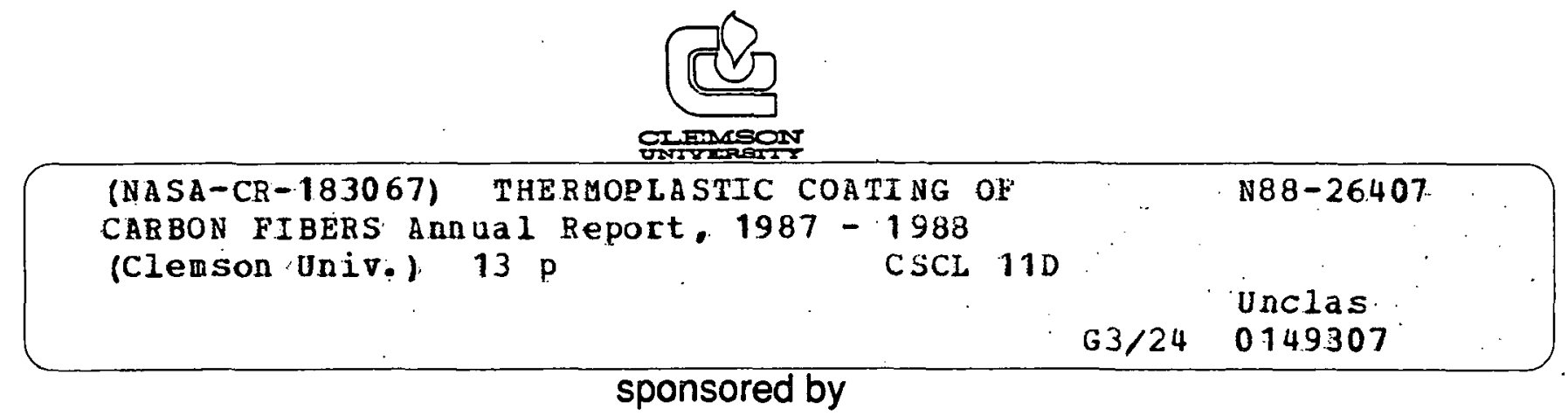

THE NATIONAL AERONAUTICS AND SPACE ADMINISTRATION : LANGLEY RESEARCH CENTER

HAMPTON, VA 23665

NASA Research Grant NAG-1-680

Robert M. Baucom

NASA Technical Officer 


\title{
THERMOPLASTIC COATING OF CARBON FIBERS
}

\author{
Annual Report
}

1987-1988

by

D. D. Edie, G. C. Lickfield, M. J. Drews, M. S. Ellison

L. E. Allen, J. R. McCollum and H. L. Thomas

\author{
ADVANCED ENGINEERING FIBERS LABORATORY \\ CLEMSON UNIVERSTYY \\ CLEMSON, S.C. 29634-0909
}

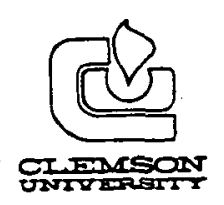

sponsored by

THE NATIONAL AERONAUTICS AND SPACE ADMINISTRATION LANGLEY RESEARCH CENTER

HAMPTON, VA 23665

NASA Research Grant NAG-1-680

Robert M. Baucom

NASA Technical Officer 


\section{Table of Contents}

Page

Introduction

1

Overview of past work

3

Process Development - June, 1987, through July, 1988

4

Stage 1 - Tow Movement and Tension Control 5

Stage II - Tow Spreading $\quad 6$

Stage III - Polymer Coating 7

$\begin{array}{ll}\text { Stage IV - Polymer Melting } & 7\end{array}$

Evaluation of Composites $\quad 8$

$\begin{array}{ll}\text { Appendix } & 9\end{array}$

Students supported by NASA grant NAG-1-680 9

Related research in advanced fibers at Clemson $\quad 9$ 


\section{Introduction}

The demand for lightweight, high performance composite materials has increased significantly over the past several years. However, in aerospace, industrial and recreational applications their use is often limited by the high cost of these materials. A recent study by Kline and Company shows that prepreg preparation and composite fabrication accounts for two-thirds of the cost of today's composite products. Therefore, if the cost of composite materials is to be significantly reduced, improvements will be required in these process steps.

Thermoset polymer matrix resins are currently the most widely used in prepreg formation. Typically, in the production of a prepreg a partially reacted thermoset resin is applied to the fiber tow. The low viscosity assists fiber wetting and improves matrix uniformity. This reduces voids in the material which, in turn, increases the strength of the final composite part. However, since a thermoset polymer is only partially reacted, these prepregs have a short shelf life and often require refrigeration before use. Also, often the prepreg sheets are manually stacked to form the composite part making the fabrication step quite labor intensive.

Today, a new generation of high-temperature thermoplastics has been developed for application as matrix polymers. Prepregs formed using thermoplastic matrix polymers could offer several advantages. Since the thermoplastic is fully reacted, thermoplastic prepregs would have a near infinite shelf life even at ambient temperatures. Stability at ambient temperature may allow thermoplastic prepreg tows to be sufficiently flexible to weave or knit into a textile preform. This preform could be press-molded or pultruded directly into a composite part eliminating costly manual lay-up.

However, it is extremely difficult to uniformly coat these thermoplastic polymers onto a fiber tow. These high-temperature polymers are insoluble in most solvents and, when an effective solvent can be found, it is often extremely difficult to completely remove during final part formation. When thermoplastics are applied as a melt, their high viscosity results in poor fiber wetting and voids in final composite. 
During the past year research carried out at Clemson University has demonstrated the feasibility of using a new method for coating thermoplastic resins onto carbon fiber tows. Initially, the tow is separated using a vacuum driven spreader chamber designed at Clemson. A recirculating powder deposition chamber is used to apply the thermoplastic powder to the spread tow. Finally direct electrical heating melts the powder onto the tow. High-temperature polymers such as LaRC-TPI, which exhibit a time-dependent melt viscosities, have been successfully applied to fiber tows using this process.

The ultimate goal of this research project is to form composite parts as well as textile preforms from the prepreg which is produced on this pilot coating line at Clemson. This report describes in detail the modular stage coating line which has been designed and built during the past year at Clemson University. 


\section{Overview of Past Work}

From May, 1986, through October, 1987, Clemson researchers investigated the feasibility of continuously coating carbon fiber tows with thermoplastics such as LaRC-TPI. Direct observations during the operation of the continuous coating process and careful inspection of the coating uniformity were used to judge the reliability and effectiveness of various polymer coating and distribution techniques.

In this investigation the thermoplastic polymer was applied to the fiber tow using a powder extruder. Though crude, this extruder provided a relatively constant application rate and showed that a reasonably uniform coating can achieved in the continuous coating process. However, it was concluded that a more advanced method for polymer application (such as a more accurate K-tron powder extruder or a fluidized bed application system) would be required. Various methods for melting the powder onto the fiber tow were evaluated. Compared to convection heating, the direct electrical heating of the carbon tow was found to dramatically increase both fiber wetting and coating uniformity. This heating method was used to produce a tow which was $70 \%$ fiber and $30 \%$ polymer by weight, a standard ratio for carbon composites.

During these evaluation tests, several operational problems with the continuous coating apparatus were discovered:

1. The tow could not be spread sufficiently to allow thorough coating penetration.

2. High roller friction resulted in excessive fiber damage.

3. The wind-up apparatus did not automatically traverse, thus, limiting the length of tow which could be coated.

4. The molten polymer built-up on the electrical rollers used to heat the tow, eventually causing loss of electrical contact.

Nevertheless, this initial study demonstrated that the new simplified powder coating technique could be used to produce a thermoplastic prepreg. However, no conclusions concerning the effectiveness of the 
technique could be reached until composite samples, thermoformed from the prepreg, were tested. In order to produce the larger quantities of prepreg necessary to fabricate these samples and correct the operational problems discovered, this initial continuous coating apparatus required extensive design changes.

\section{Process Development - June, 1987, through July, 1988}

The objective of the NASA sponsored Clemson University research has been to develop a continuous process for the application of LaRC-TPI and other high temperature thermoplastics to a carbon fiber tow, forming prepreg which can be used in the manufacture of textile preforms. Since individual filaments are being coated as opposed to the entire tow bundle being encapsulated, this material can retain the flexibility required for textile processing.

The necessary design changes have been completed and an improved prepreg production apparatus is now in operation at Clemson. The process consists of four individual stages: tow movement and tension control, tow spreading, polymer coating, and polymer melting. A simplified diagram of the coating line containing these four individual stages appears in Figure 1. The line is designed to coat a continuous

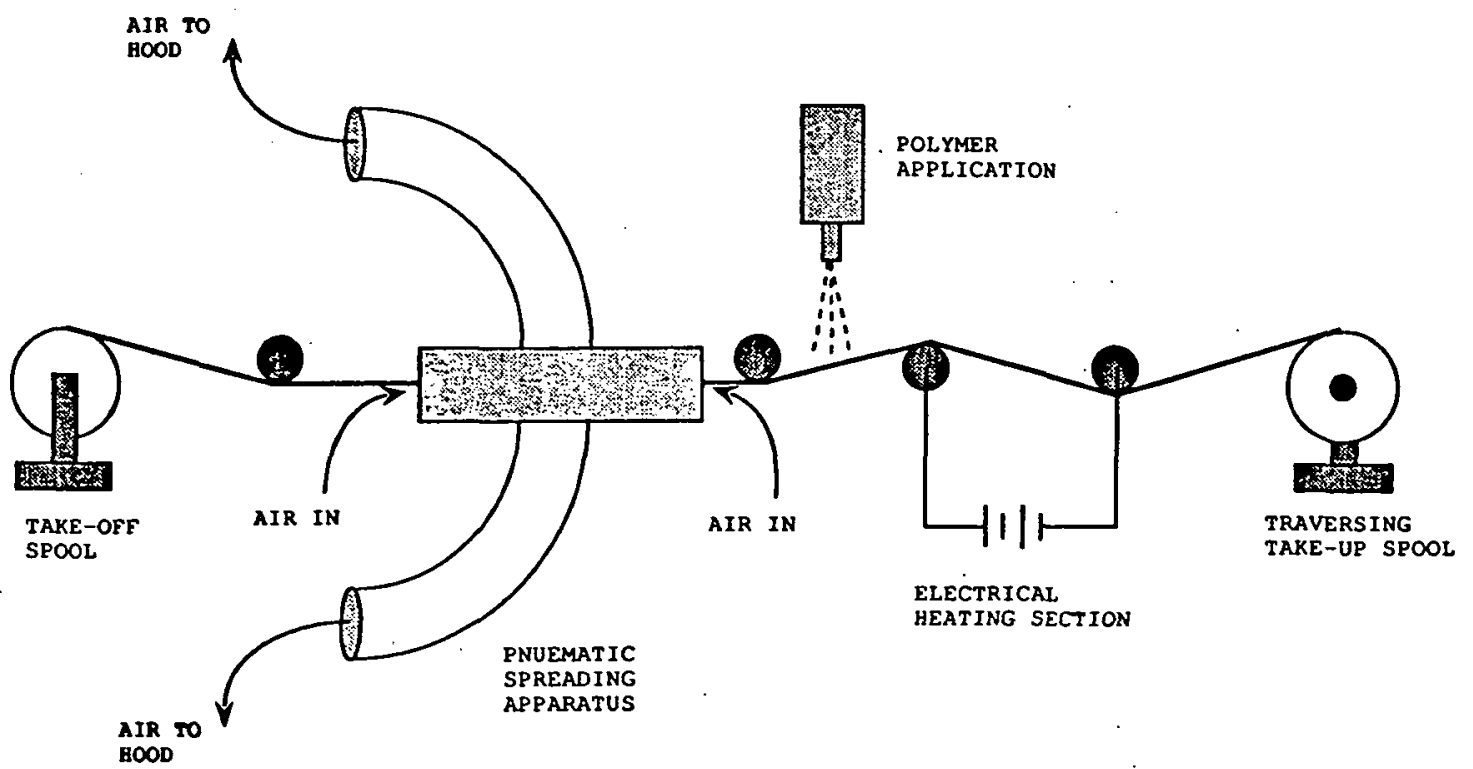

Figure 1. Schematic of modular powder coating line. 
standard spool of carbon fiber with LaRC-TPI, PEEK, polyester, or similar thermoplastic materials. Line speeds of up to 1.5 meters per minute are possible.

\section{Stage I - Tow Movement and Tension Control}

In order to maintain uniform spreading of the fiber tow, it must be transported through the process at a constant speed and tension. To provide a constant speed, a synchronized, electrically driven feed and traversing take-up system was developed. Figure 2 shows a mechanical detail of the new traversing take-up system which winds the fiber on a standard $28 \times 7.5 \mathrm{~cm}$ spool. The wind-up spool is traversed instead of the on-coming tow in order to avoid the use of a moving guide

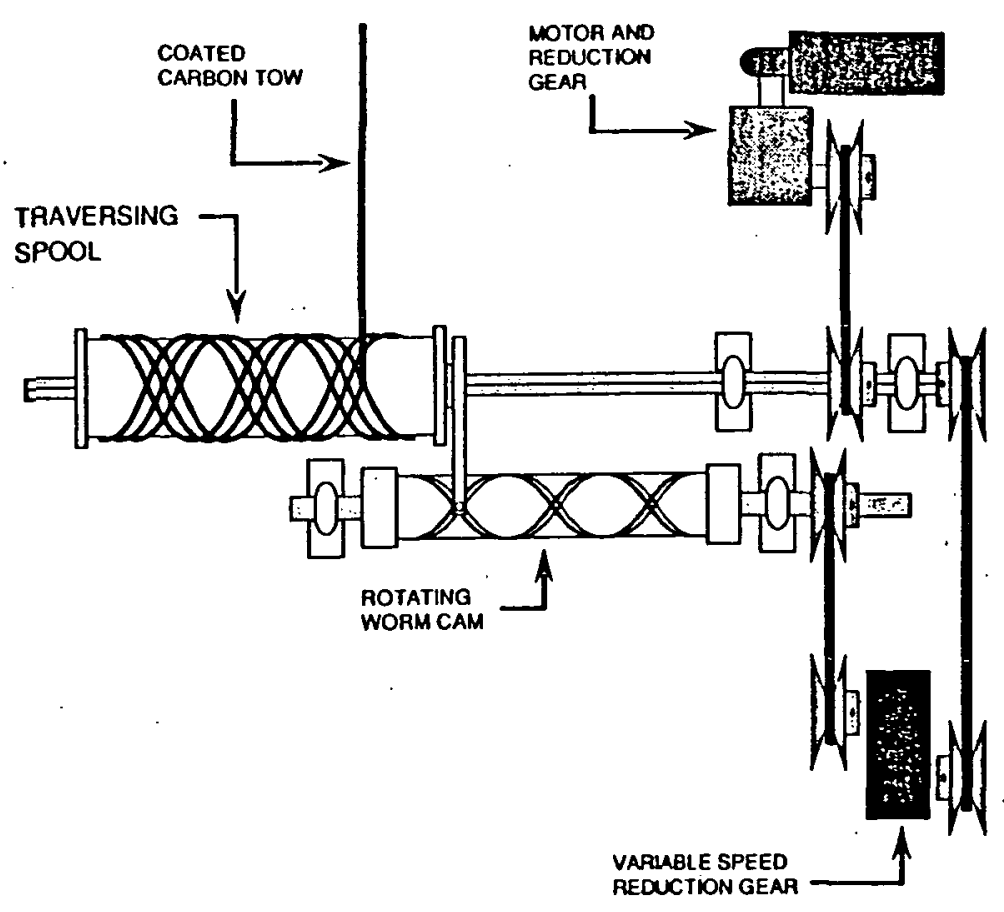

Figure 2. Transversing take-up system.

and, thus, minimize fiber breakage. Also, this winder permits the tow to be traversed without creating any increase in tension. A tension monitor is used to automatically adjust the speed of the feed motor, 
guaranteeing a constant tow tension. Also, to reduce tow tension, new polished graphite rollers on low friction bearings are being used to transport the carbon fiber tow. These rollers were designed to minimize the tension required to move the carbon fibers from take-off to take-up and thereby decrease fiber damage.

\section{Stage 11 - Tow Spreading}

Tow spreading is being accomplished using the newly designed pneumatic spreader chamber illustrated in Figure 3 . This chamber was designed and built by Clemson University researchers with the help of Clemson University Engineering Services Division. The carbon fiber tow

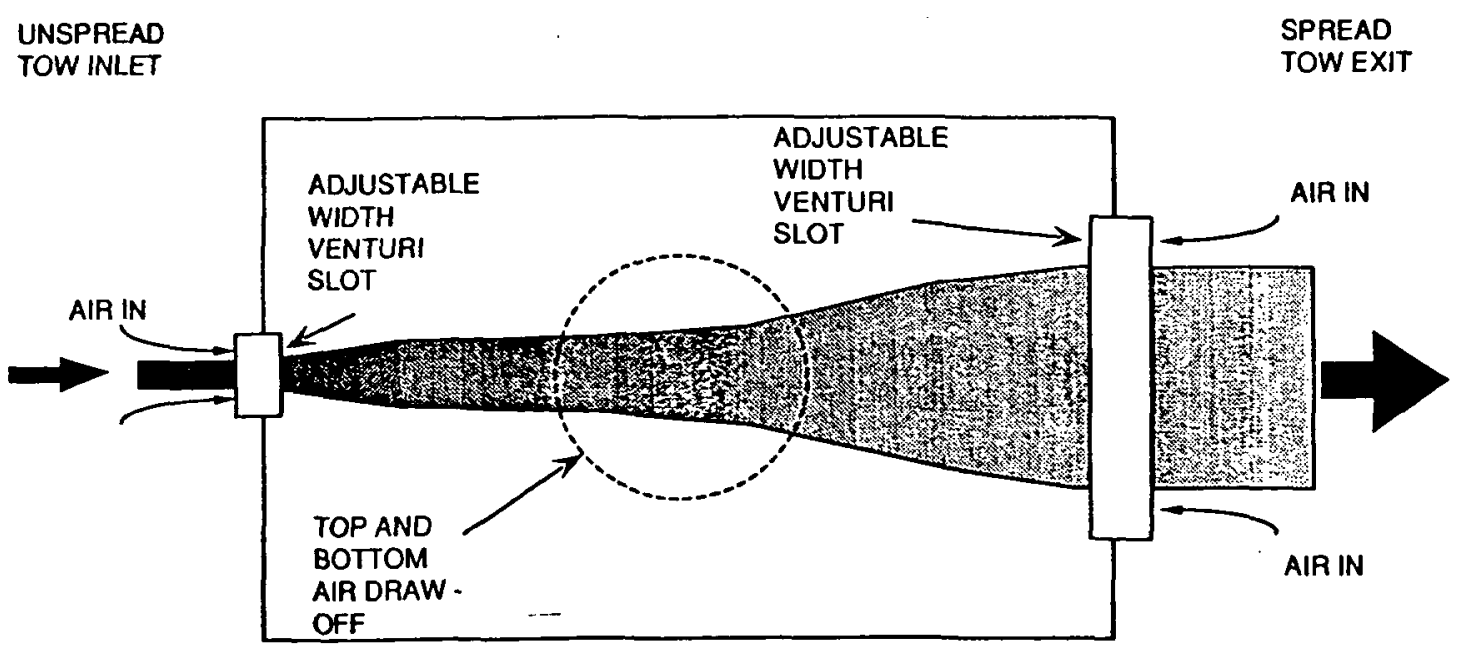

Figure 3. Pneumatic spreader chamber.

is spread using the venturi-like flow pattern which is produced when air enters the chamber through a small orifice. Since only the air flow spreads the carbon tow, the friction required to spread the bundle is minimized. The width of the spread tow may be changed by adjusting the air flow rate, tow tension, or exiting slot width. 


\section{Stage III - Polymer Coating}

LaRC-TPI and other high temperature thermoplastic powders used as matrix resins can be applied to the spread fiber tow using a recirculating powder deposition chamber. Figure 4 shows the powder coating apparatus (also designed and built during the past year at Clemson). Inside the chamber, the fiber tow passes through a region of minimal air velocity. To maintain a constant concentration of thermoplastic resin inside the chamber during operation, powder enters continuously through a nitrogen stream. This also serves to inert the atmosphere inside the coating chamber.

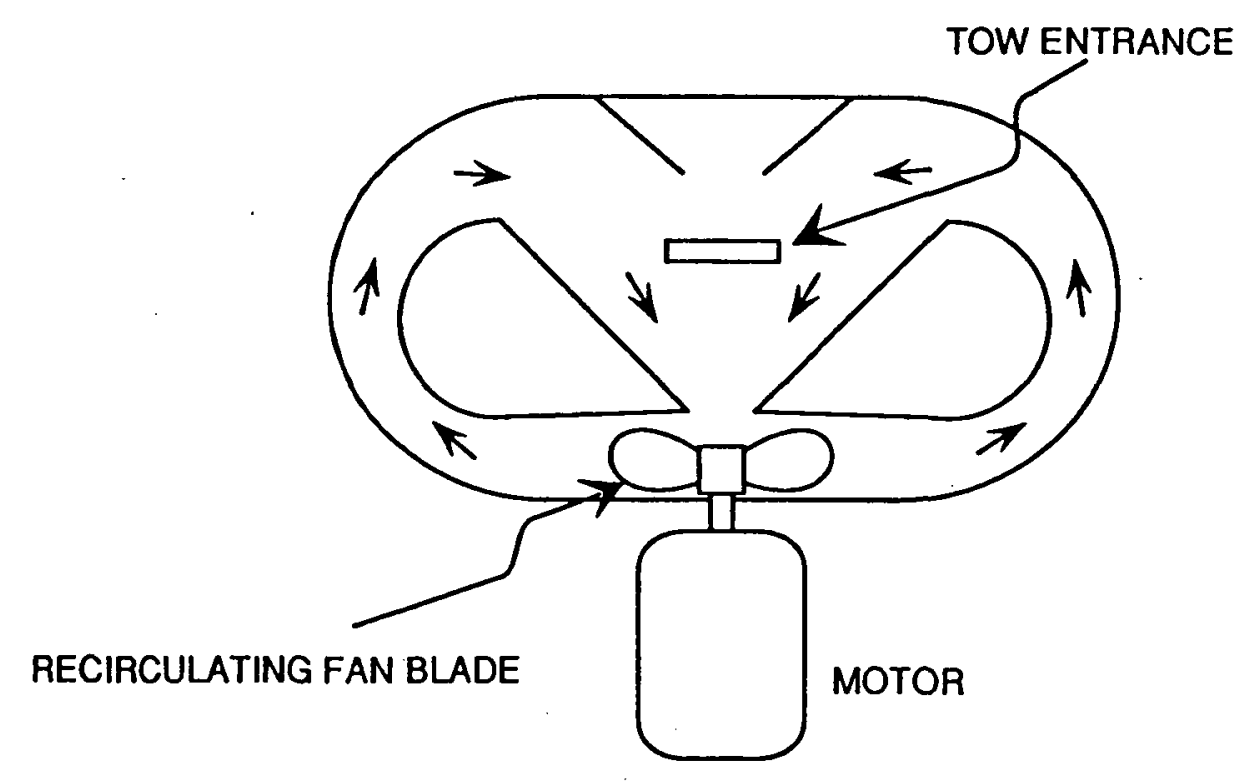

Figure 4. Recirculating powder deposition chamber.

\section{Stage IV - Polymer Melting}

The thermoplastic resin is melted onto the carbon fiber using electrical resistance heating. The tow passes between two gold coated electrical contact rolls to which a current of $30-40$ volts is being applied. These rolls have been electroplated with gold to reduce the 
contact resistance, thereby reducing the incidence of sparking . A convective heating module has also been designed and fabricated for use either as an independent heating technique, or as an additional heat source when simple electrical resistance heating is inadequate.

Microwave heating is presently being investigated as an alternative heating method. Initial trials show that the microwave radiation has sufficient energy to heat small quantities of fiber in a batch process. A microwave heating unit is now being designed for integration into the continuous coating line.

\section{Evaluation of Composites}

Now that quantities of prepreg have been made on the thermoplastic coating line at Clemson, they are being formed into both textile preform structures and directly into composite samples. The textile preforms include both woven and knitted structures which will be thermoformed into a finished part. In order to determine if the matrix resin is properly adhering to the fibers or if voids are being formed in the coating process, the tensile strength and modulus of these samples will be tested at Clemson University. The matrix uniformity of matrix distribution in these samples is also being determined using an image analyzer. 


\section{Appendix}

Students supported by NASA grant NAG-1-680:

Janet R. McCollum; Master of Science in Textiles (expected graduation - 1988)

Laurence E. Allen; Master of Science in Chemical Engineering (expected graduation - 1988)

Howard L. Thomas; Ph. D. in Textiles (expected graduation - 1990)

Related research in advanced fibers at Clemson:

Student Degree Thesis Topic

1. Mike G. Dunham Chemical Engineering Ph. D. student Thermal Treatment of PAN

2. Helen E. Gainey Chemical Engineering Ph. D. student Failure Modes for Carbon Fibers

3. Abhijit Banerjee Chemical Engineering Ph. D. student Fiber/Matrix Bond Strength

4. Shien Fu Wang Chemical Engineering Ph. D. student Thermal Aging of Composites

5. Keith Hutchenson Chemical Engineering Ph. D. student Extraction of Mesophase

6. Johannes Roebers Chemical Engineering Ph. D. student Extraction of Mesophase

7. Laurence E. Allen Chemical Engineering M. S. student Thermoplastic Coating C-Fibers

8. Gary Hayes Chemical Engineering M. S. student Melt Spinning Carbon Fibers

9. Janet McCollum Textiles M. S. student Thermoplastic Coating C-Fibers

10. Howard Thomas Textiles Ph. D. student Knitting and Weaving C-Fibers

11. Kou T. Tzou Textiles Ph. D. student Solvent Extraction of Mesophase

12. Robert Schikner Ceramic Engineering M. S. student Melt Spinning Carbon Fibers

13. William Dubose Ceramic Engineering M. S. student Melt Spinning Carbon Fibers

14. H. Edward Rast Ceramic Engineering M. S. student Heat Treatment of Carbon Fibers 